\title{
Dinner and a Conversation: Transgender Integration at West Point and Beyond
}

\author{
Morten G. Ender*, Diane M. Ryan, Danielle A. Nuszkowski, Emma Sarah Spell and \\ Charles B. Atkins \\ Department of Behavioral Sciences \& Leadership, United States Military Academy, West Point, NY 10996, USA; \\ diane.ryan@usma.edu (D.M.R.); Danielle.Nuszkowski@usma.edu (D.A.N.); emma.spell@usma.edu (E.S.S.); \\ charles.atkins@usma.edu (C.B.A.) \\ * Correspondence: morten.ender@usma.edu
}

Academic Editors: Maralee Mayberry and Lane Hanson

Received: 31 December 2016; Accepted: 3 March 2017; Published: 8 March 2017

\begin{abstract}
In 2016, the United States military lifted the ban on transgender members serving and are expected to begin accessions of transgender service members in 2017. A paucity of research exists on transgender matters in the military, especially on attitudes towards cisgender service members. This study deploys a qualitative methodology, comprised of 21 focus groups of undergraduate cadets and advanced schooled Army officers $(N=110)$, at the United States Military Academy at West Point, New York, using a semi-structured interview protocol. Overall, a diversity of experiences and familiarity with transgender people surfaced among cadets and officers. We distinguish between experiences and familiarity on a spectrum by introducing notions of transgender tourism and cosmopolitanism. Major concerns associated with (un)comfortableness emerged from the focus groups including privacy, physical standards, well-being, and costs. Interventions are offered by the participants based on their major concerns. We recommend education, increased cosmopolitism, privacy considerations, narrowing the civil-military propinquity gap, and more studies of diversity and inclusion issues in the military.
\end{abstract}

Keywords: transgender; military; undergraduates; attitudes; youth; cadets; military academy; soldiers; U.S. Army; focus groups

\section{Introduction}

Caitlyn Jenner and Chelsea Manning brought transgender matters to the forefront of American national discourse in unprecedented ways [1,2]. With the repeal of the U.S. military's 'Don't Ask, Don't Tell' policy on 20 September 2011, gay, lesbian, and bisexually oriented military service members could for the first time serve openly without fear of formal institutional sanctions, specifically military separation. The "Don't Ask, Don't Tell" (DADT) repeal excluded the 'T' of LGBT people, although transgender soldiers have served clandestinely in the military since the nation's inception [3-5]. The U.S. military more recently lifted the ban on openly transgender service on 30 June 2016. The new Department of Defense Implementation Handbook provides important guidance for military leaders at all levels to manage both their cisgender and transgender military talent [6,7]. We undertook an applied qualitative study to explore the experiences, major concerns, and recommendations that youth and officers at an American military academy have regarding the anticipation of integrating transgender cadets and soldiers into the U.S. Army.

The civilian and military numbers on transgender identity are compelling. The Williams Institute estimated the number of Americans self-identifying as transgender at roughly 700,000, comprising approximately 0.3 percent of the U.S. adult population [8]. Further, an estimated 15,450 transgender service members serve in the U.S. armed forces, and there are 134,350 transgender veterans. A 2008 
survey of transgender veterans found notable diversity, including that almost two thirds (64\%) identified as male-to-female (MTF) and just over a third (38\%) identified their sexual orientation as heterosexual [9].

Due to their past prohibitive status of serving openly, there exists a paucity of research focused on transgender people in the military [3,4,10-13], but the limited scholarship is rich and worth highlighting to frame problems encountered during and post-military service, strengths of transgender service, and what is known about attitudes towards the intersection of gender non-conformity and the military, a youth-oriented organization with most service members in their early 20 s.

At the individual level, almost half of all transgender veterans reported suffering psychological distress, and many reported the medical and mental health care systems contributed to their distress through further victimization [11]. Moreover, the prevalence of gender identity disorder among Veterans Health Administration users virtually doubled over a 10-year period, and the suicide rates are statistically higher for this veteran population as well [14]. More in depth, transgender veterans reported a host of social problems including bureaucratic roadblocks, harassment and discrimination, incarceration, family rejection, and homelessness [12]. A first of its kind qualitative study of a small sample of clandestinely serving transgender people in the U.S. military confirms earlier research, including feelings of distress, seclusion, disconnectedness, and, understandably, a lack of mental or medical health services provided by the military at the time [15]. Cross-nationally, prior to the repeals of LGBT exclusion in the U.S. military, the U.S. scored markedly low compared to the inclusion of LGBT among other all-volunteer military countries [16], lagging behind the English-speaking world in policy reassessment [17].

Far less problematic, a comprehensive study of transgender people in the Canadian military found that openly serving transgender service members posed no problems to organizational performance or effectiveness [18]. An online survey, the National Transgender Discrimination Survey, asked respondents about their military service and found that transgender Americans serve in the military at twice the rate of the U.S. population [12]. A recent RAND Corporation study concluded, based on previous integration efforts of other historically disenfranchised groups and a review of transgender service members in foreign militaries, that there would be little to no impact on areas of readiness to deploy, unit cohesion, and operational effectiveness [19]. Indeed, a fairly recent study concluded there to be limited consistent medical or psychological evidence for barring transgender people from serving in the U.S. military, irrespective of their gender identity [8]. Notably, 60 percent of separated service members within the last 10 years reported on a survey that they might or would return to service if the transgender ban on service members were lifted [13], reflecting perhaps their collective loyalty, commitment, and sense of duty to military service.

Attitudes do not always predict behavior; however, research has shown that global attitudes are correlated with behavior [20]. Attitudes are important to gauge, especially across time and in organizations, as they provide leaders, in our case mostly future leaders, with a measure to assess organizational changes and the social psychology of organizational members. For example, positive attitudes toward gays and lesbians during the 2000s correlated with increases in the number of states adopting same-sex marriage policies [21]. Likewise, attitudinal shifts toward greater acceptance of gays and lesbians in the military likely contributed to the repeal of DADT [22].

Studies of attitudes toward transgender people are sparse, notable, and primarily quantitative. The published literature through 2012, including cross-national research, found that all but two of the studies across 25 years had used nonprobability samples and college students [23]. The overall finding for studies asking about transgender people from U.S. adult samples suggest significant negative attitudes and discrimination [23]. Most of the research, including studies of university students, found that men, the uneducated, older, and highly religious people hold more negative attitudes toward gender nonconforming people [24]. Recent research on youth fortifies previous studies [24-28]. Findings comparing cadets and civilian undergraduate peer attitudes revealed race/ethnicity, sex, politics, and military affiliation as discriminating variables regarding the role of women in the 
military [29], gays and lesbians in the military [30], and transgender military service [31]. At the precipice of lifting the ban on transgender service, we undertook a qualitative study to gauge the social environment among cisgender cadets and officers regarding open transgender people in the U.S. Army.

In the present study, we use a qualitative design to explore three areas: (1) cadet and military faculty and staff education and experience with transgender people; (2) personal perceptions about the impact of transgender people on good order and discipline in the Corps of Cadets at the United States Military Academy and the U.S. Army; and, finally, (3) perceived perceptions of respondents about how fellow cadets and soldiers might think transgender people will impact good order and discipline generally at both West Point and the U.S. Army.

\section{Background on West Point}

West Point, the United States Military Academy located in the Mid-Hudson River Valley 50 miles north of New York City, was championed by President Thomas Jefferson and established under his presidential administration in 1802. Other military-oriented service academics, both public and private, have been established in the United States, but West Point remains the oldest. West Point now produces approximately 25 percent of active duty U.S. Army officers with each graduating class (roughly 1000, including a handful of foreign military officers). The Reserved Officer Training Corps (ROTC) on American college and university campuses and Officer Candidate School (OCS) produce the remaining bulk of Army officers. All four classes of cadets are housed on the military installation and much of their lives are regulated by institutional norms and sanctions. West Point is an accredited institution of higher learning by the Middle States Commission of Higher Education as a degree-granting institution [32]. West Point has a fairly traditional academic curriculum, offering over 40 major and minor areas of study modeled much like civilian institutions of higher education that offer Bachelor of Arts (B.A.) and Bachelor of Science (B.S.) degrees [33]. West Point and its sister academies, the United States Naval Academy, the U.S. Coast Guard Academy, and the U.S. Air Force Academy, are run by the federal government.

Potential cadets apply much like they do at traditional civilian colleges, and the ages of incoming first year students (plebes) are between 17 and 23, but they are not allowed to be married or be a custodial parent; 80 percent are 21 years of age or younger. Notably, for full consideration for admission, a completed file requires nominations from Congressional Representatives, Senators, the Vice President, or the President. Typically, a mere 10 percent of full applicants are accepted. The Academy has a purposeful diversity effort, wherein cadets are recruited and accepted across all 50 states in order to represent the geography of the United States, and racially and ethnic minorities are recruited for proportional representation to the U.S. population. Women's percentages are on the rise following the lifting of their exclusion from combat specialties. Most notably for the present study, West Point follows the major policies of the United States Government, the Department of Defense, and the Department of the Army. Essentially, social policies impacting the U.S. Army such as the repeal of the Don't Ask, Don't Tell policy and the lifting of combat exclusion for women, are implemented at West Point. Essentially, so goes the Army, so goes West Point.

\section{Methods}

As an exploratory study of the wider population of cadets and West Point faculty and staff, we rely on a qualitative research design.

\subsection{Sample}

For a robust sample and breadth of voices, we opted for focus group interviews. We conducted 18 focus groups with cadets and three with staff and faculty, totaling 110 total participants during the late fall of 2015 and early spring of 2016, all prior to the U.S. military repealing the ban on transgender service members on 30 June 2016. The bulk of the cadets were first year students, commonly known as 
'Plebes' $(n=50)$, enrolled in a required Introductory Psychology course and juniors, known as 'Cows' $(n=35)$, enrolled in a required Military Leadership course. The military faculty and staff comprised active duty U.S. Army Captains to Colonels, including one Staff Sergeant. All of the officers had advanced academic degrees or were completing them, namely Master's and PhDs, all from accredited civilian graduate programs, including Duke University, Columbia University, and the University of Wisconsin, among others. A typical focus group had five participants, including two staff and faculty focus groups with two participants each and one as large as 10 participants. The focus groups lasted an average of $44 \mathrm{~min}$; the range was 38 to $69 \mathrm{~min}$ for a total of 1014 focus group minutes. People of color and women were well represented among the focus groups. The focus groups represented the racial and sex distribution of West Point fairly well, with 33 percent comprised of cadets of color and 20 percent female. The focus groups yielded 382 single spaced pages of transcription.

\subsection{Procedures}

The study received an Institutional Review Board (IRB) exemption at West Point. The IRB determined that the research posed no risk to subjects greater than what the subject would encounter in routine life experiences. We then solicited all military faculty and staff, and half of the entire classes of Plebes and Cows enrolled in 'Introductory Psychology and Military Leadership' respectfully during the fall semester. We also used Cow cadets $(n=12)$ from a sociology course to pilot the questions. We included the pilot focus group in the present study data. All cadets received extra credit in their courses for participating in the study. Both faculty, staff, and cadets received notification electronically. We proffered various times to accommodate cadet and military member schedules.

The procedure involved focus group interviews of about one hour in length that took place in a research classroom at West Point. Focus groups were audio-taped using two separate recording devices. At least two members of the research team were present for each focus group. After the interviews, participants received information about whom to contact should they have questions or concerns regarding their participation.

The audio-taped interviews were transcribed by an outside agency. A Memorandum of Understanding between West Point and the transcribing company was initiated and sanctioned to assure confidentiality, anonymity, and privacy of the raw data. Once the data were transcribed digitally, the senior Principal Investigator reviewed each transcribed document with the digital audio and de-identified the data for anonymity, privacy, and confidentiality. Both the raw digital audio files and the raw transcripts were then permanently deleted. Care was taken not to identify anonymous individuals (e.g., Plebe, female, Asian-American) in both the de-identified transcripts and in the quotes put forth below in the results section.

A two-fold data analysis based on previous studies of military populations guided the present study [34]. First, each focus group included two investigators. One investigator ran the focus group using the semi-structured interview protocol. The other took notes and had the responsibility to return to any questions on the protocol at the end of the interview if they had not been adequately covered. This assured both breadth and depth. Following each focus group, the two investigators took time to debrief one another using a theoretical sampling strategy oriented in the grounded theory approach within the context of the semi-structured protocol. We also accounted for any serendipitous findings. This technique informed follow-on focus groups. Second, the investigators conducted an overall, independent analysis of all the focus group de-identified transcripts (382 pages), yielding a 90 percent inter-rater reliability agreement.

\subsection{Measures}

Based on some specific social dimensions the Department of the Army had regarding transgender service members, we sought to answer some fundamental themes as an exploratory study. We focused on three objectives. First, we were interested in perspectives on the meaning of transgender for cadets and military members. Second, we wanted to gauge the level of personal connection and experience 
with transgender people and communities. Last, we wanted to gauge what respondents thought the major concerns and solutions would be for having transgender service members serve openly at West Point and in the larger Army.

\section{Results}

The results have four sections; meanings of transgender, personal experiences, major concerns, and interventions. The results are reported as quotes and are presented to represent a typical majority of respondents unless otherwise stated.

\subsection{Meanings of Transgender}

First, we were interested in perspectives on the meaning of transgender and gender non-conformity for cadets and military members. There was a 17-year long build-up for the military to become acquainted with gay, lesbian, and bisexual service members through the DADT policy. However, the transgender community is relatively small compared to the LGB community and the build-up to repeal much narrower. Thus, we anticipated that familiarity with transgender notions would be sparse or narrow at best, and indeed this is the case for the typically inexperienced; the younger, first-year, rural-oriented, and military inexperienced subjects in our study.

Most cadets and a few military members interpreted transgender to mean transsexual. Essentially, for most, transgender implied a binary definition associating sex exclusively as either male or female. As two first year cadets responded; 'Someone who has had a sex change operation' or 'Someone who thinks they are the other gender or acts as the other gender'. When asked, 'What pops into your head when I say transgender?', a typical response was 'Just male, female; that just pops into my head'. Many alluded to Caitlyn Jenner and her sexual reassignment from the male formerly known as Bruce Jenner. The overwhelming majority of the respondents had this binary view. Few thought of transgender as a broader orientation representing a host of sex or gender related characteristics on a spectrum or as an umbrella term.

The groups that did think more broadly are in the minority and included most of the active military members and some cadets with either education and/or experience with transgender people or issues. An active duty service member says they think of 'gender fluidity' when they think of transgender. Likewise, junior level cadets (all sociology majors) in our pilot group, who had completed a number of sociology courses including 'Introductory Sociology; Social Inequality; or Marriage and Family', where the topic is broached objectively and systematically, indicated a more nuanced understanding of transgender. A typical response is offered by a sociology major; 'I think being transgender is recognizing the fact that society expects people to assign their gender with their sex. Society expects that there is only male and female. Someone that's transgender feels as though the characteristics of a certain gender more reflect how they feel inside and that just happens to [conflict] from their sex'.

\subsection{Personal Experiences}

Again, we began our focus groups attempting to gauge the level of familiarity and experience with transgender people and communities respondents might possess. While we heard a great deal of social distance between our respondents and transgender individuals and even the transgender community, we did also hear some patently rich stories of personal connections.

The majority of the respondents had no direct experience with anyone transgender or the transgender community. Their only experience came from mass media (e.g., Caitlyn Jenner). They had little to share, and, when probed, a majority of these respondents qualified that they grew-up in more rural or suburban parts of the United States and attended high schools in these regions before coming to West Point or heading off to college. Most were familiar with the acronym LGBTQ, many less with the ' $Q$ '. Others appeared to feign knowledge not to appear uninformed. Many reported they had had no LGBTQ student group or Gay-Straight Alliance on their high school campus. These included 
cadets and military members from rural areas, Christian-affiliated single-sex schools, and most home schooled individuals. A cadet responded about the LGBTQ folks in his community; 'No, [LGBTQ] is not well known. The only time, really, that groups no one knows about comes up is if it comes up in the news'.

More than half the cadets and almost all the officers had at a minimum some modest experience with the LGBTQ community, and some had transgender acquaintances or friends. One distinguishing feature resulted from the region of the country they grew up in. Cadets from urban metropolitan areas such as Seattle, Los Angeles, Denver, New York City, and San Francisco, among similar large cities, had significant familiarity. Indeed, for all cadets from such locales, they made direct and significant associations between their fluency with transgender matters and living in an urban metropolitan area.

Similarly, cadets from urban and some suburban high schools had had a LGBTQ or a Gay-Straight Alliance of some sort at their school. A female cadet shared; 'It [the Alliance] is pretty active. I mean, I was never in it, but if somebody invited me to a meeting, if I had a good reason to go, I would have'.

Another small group of cadets had significant and direct familiarity with transgender people. After some cadets shared that they had been to Drag Queen shows ('Drag Queens' are men who dress and perform on stage as women, but the definition can be more nuanced) [35], another cadet confided attending with their mother. When asked why, the cadet said; 'Well, I thought it was interesting. My mom has been to some. I have a gay brother and his roommate is actually transgender, he lives in Seattle'. Sharing more about gay bar experiences and the cadet's comfort level there, the cadet goes on:

I think having a gay brother helps me feel comfortable with that. There's a program called It Gets Better [http:/ / www.itgetsbetter.org/] where people, I don't know if you guys have heard about that, but people will talk openly about LGBT acceptance. Either gays telling their stories and say, this is how I overcame the social pressure or whatever, or Straight Allies, as well getting support. They did one my plebe year on West Point. I don't think it ever got published or anything. But I was a part of that as a Straight Ally. I talked about, like my brother's struggle, and so, I think that helped make me feel more comfortable. ${ }^{1}$

A first year cadet's mother worked as a human service provider with sexual minorities in a rural Midwest community. The cadet shared:

When I was really little, my mom started working at the AIDS Foundation, and as bad as it may sound, the AIDS Foundation does work a lot with LGBT people. Since she was outreach, she would go out to clubs and she would go out to street corners and she would find people and teach them how to protect themselves. So if you are in that kind of job, you do not have room to judge people. You are literally seeking out prostitutes and strippers and all kinds of people that society pushes away and saying here is how you can take care of yourself. So I was not sheltered at all and my mom was like; you are going to learn about the real world. So she would have me chug along behind her at work and she would be like tell this person about chlamydia and I would just pop off about this and that STD because I would sit in her office and read STD pamphlets all the time and talk to her clients. I did not think it was weird, but I guess for other people that is weird.

A senior Army officer shared a heartwarming story about a graduate school friend and an experience after the officer had arrived at West Point:

So somebody that I am not in contact with anymore, not because of that but just because of more physical separation, but a person that I became friends with in one of my graduate school experiences and was born a male and was a male at that time. We left and kept in loose contact over the years. I found out years later. My wife and I were friends with him

1 All quotes originate from the 392-page master de-identified transcript file of the 21 focus groups. 
and his wife and that he went through an experience where he felt that he was the wrong gender and he wanted to change that. They had children involved and so it was very complicated. [How old was he?] He would have been in his mid 30's. For me, when I went and we just happened to be in the town again and went and had dinner with them and I can just remember, especially at that time when it really wasn't in the press as much as it is now, where you didn't have much time to think about what it meant, I can remember being very, very, uncomfortable going to meet. I was going through all the questions. Do I call 'him,' do I call him a 'her'? Do I call him the name that I called him when we were friends before? Do I call her the name that she has adopted now? She was probably about 75 percent through the process [sex reassignment] at that time. I had not seen her since that event. But friends that we had at the time and it was just one of those things that I didn't understand and I can remember being uncomfortable about it. It all ended well. Ended well for her now and the previous family who we still stay in contact with and not something that I had thought about prior so it was on the fly learning for me.

When the moderator asked, 'What helped you get through being uncomfortable?' the officer replied, 'Dinner and a conversation. No really'.

\subsection{Major Concerns}

We engaged the focus groups about what they regarded to be the major concerns they anticipate both at West Point and in the larger Army should the transgender exclusion policy be lifted. Major concerns include social issues such as privacy and physical standards, psychological dimensions including the well-being of both cis- and transgender cadets and soldiers, and economic issues such as the costs associated with sexual reassignment transitioning among soldiers. Both social and psychological issues are nuanced by feelings of comfortableness.

Privacy was identified as a major concern in terms of personal privacy and perceived concern for other cadets and soldiers in the larger Army. Privacy issues include the general and the specific. Many cadets anticipated private bathrooms being a major concern, but most said they would be 'Okay' with public gender-neutral restrooms. However, not all said this. For example, one female cadet responded; 'I think a woman is still a woman and a man is still a man if you are gay or lesbian. The discomfort with sharing a bathroom with someone who is still physically male, you might have to worry about if they are different'. A male cadet said: ' . . and the bathrooms and all that stuff is also serious, but I think when you're putting lives at risk and such that it becomes different'.

Showers are a privacy issue. Cadets anticipated that community or shared showers could be problematic. A cadet simply said; 'Where do they shower? I don't know'. An officer replied somewhat sarcastically; 'Are we going to have 'Starship Trooper' showers?', referring to the shower scene in the 1997 film of the same name depicting a future military academy where male and female cadets shower together with no sexual intimacy associated with the scene. Showers are seen as especially problematic if they are open showers. A cadet noted; 'Depending on the barracks, which shower? Scott and Grant [barracks names at West Point] are open area showers'. One twist on the shower came from a cadet:

I think you gotta look at it from different sides too. You gotta take the sides of everybody if you are going to be truly diverse and inclusive. That includes heterosexual people who believe a certain way as well. I thought that was the thing I learned from the transsexual that I had talked to. They were careful in the gym; people in the gym working out and then he is like, 'Hey, I am not going to shower in the gym,' and all that because it is taking into account the feelings of other people, too. I thought that was kind of interesting. I think that is probably the thing I learned most is you gotta kind of take this as everybody is human beings and you gotta kind of take into account other people's feelings, not just your own agenda. I thought that was the biggest lesson that I learned from the whole thing. 
Another privacy major concern is living arrangements. Cadets wondered how people would share rooms. West Point currently houses straight and gay, lesbian, and bisexual cadets together. The vast majority of cadets reported being 'fine' with the arrangement. They do see anatomy, not sexual orientation, as a distinguishing feature. However, they do not perceive the same logic with transgender cadets and soldiers, and some struggle with making sense of the arrangement. In the focus groups, participants often came back to anatomy, i.e., genitalia should room with like-genitalia. They likewise extrapolated to soldiers in the broader Army as well, who they perceived would have difficulty with similar living arrangements. A cadet with prior enlisted military service shared:

I'd say the barracks life, living in close proximity to something you're just so unfamiliar with. A lot of people don't even know what the T in LGBT means, never mind living with someone who is transgender. Even I'd be a little bit cautious and a little bit surprised by it. I don't know, soldiers especially in basic training or something, or deployment, in a barracks with somebody they're really not familiar with.

Physical standards associated with transgender cadets and soldiers are another major concern theme that emerged in the focus groups. Physical standards are associated with the mandatory Army Physical Fitness Test (APFT). A male cadet notes:

I think another implication that might be brought up is the physical standards ... [those] that we are doing now. For example, like male fitness standards, female fitness standards, and if a female decides that she wants to become a male or vice versa. Those, they would be held to entirely different standards than they were used to. I think, would that be fair or how would they make that transition?

Representing the views of others, a female cadet emphasized the potential unfairness of possibly gaming the PT standard system. She tried to highlight the issue:

I think there is another like a big issue ... somebody mentioned PT standards. When you think, why are men held to higher PT standards than women? It is just like, their physical capacity, they are able to do more, so just because you change from a man into a women, do you still not have that physical capacity to do more? So then, are you now held to the women's standard where you will be able to do more than the women because, still physically, you have the strength a man would have. Vice versa, as a woman transitions, she will not have that physical capacity naturally that a man would have.

When asked about major concerns, both officers and cadets offered up what we categorize as the issue of well-being. The officers that responded regarding well-being consistently had the best interests of a transgender person in mind. Cadets more often thought about the well-being of the majority cisgender cadets and less about the transgender cadet. Yet, a handful did express their concern for the transgender cadet.

The term most often associated with interactions both personally and serving as a fellow cadet leader, peer, or subordinate was 'uncomfortable'. This included how they thought soldiers in the Army would interact with a transgender soldier. When we probed more on their personal interactions, virtually all did indicate a minimum level of tolerance. Some went further and offered that they could champion a transgender cadet (more on this below in the section on pragmatic professional).

First, a dominant theme for cadets was that there would be less tolerance among American soldiers toward transgender soldiers. One cadet supposed:

I think there could be a tolerance issue because I feel like many times when people go to college it is a big step into a whole new pool of diverse people that they have never encountered before in their hometowns. So I think those two to four years of college really help somebody transition into being more tolerant, and, depending on whoever this person may be or where they came from, jumping right into the Army from high school and 
having only that experience from where they are from may make them more prone to being intolerant and more affected by transgender, homosexuals, or whatever.

Another cadet represented the argument that, for LGBTQ cadets, West Point would add an additional role strain because of its major feature of your identity:

I think for the individual just the amount of stress that you're put under. It's already like a very stressful program here [at West Point], even if you didn't have anything else going on like that. So, like a really stressful process. I mean it will effect, for them it will affect, I guess, performing like an athlete. Or academic, how they're doing in class and also, I guess in general, their overall mental well-being or mental health. That much stress is an issue of, you know, mental health and mental well-being.

Again, cadets often used the term 'uncomfortable' in the focus groups. The implication is that cisgender cadets would be uncomfortable with transgender cadets in various capacities. In an example of roommates, a female cadet represented the theme:

I was going to say in the barracks like for her she would probably room with a female but if that female was uncomfortable having a male anatomy in there that it would be kind of be hard to like choose a side. It would be like okay she identifies as a female but at the same time she still has anatomical perception of a male, so is this female uncomfortable living with her?

We did probe about why someone might feel uneasy rather than curious and open about someone different from them. Cadets more often seemed to imply change is not what they would expect to find at West Point. A cadet shared about cisgender cadets not exposed to diversity, perhaps those coming from rural areas, stating:

As you say, I think it's going to require a lot of education. I know a lot of people who don't necessarily like things that they don't understand initially. And coming from different areas ... in Tennessee, we definitely didn't have these gay support groups or alliances. It was definitely not a thing. So people coming from certain areas and households and stuff are probably going to be more averse to it than others. So definitely there will be huge steps needed to make sure people are comfortable.

A minority of cadets said they would not be bothered by a transgender cadet and they would actually be fairly comfortable. For example, a cadet said simply; 'I don't give a shit. As long as they can do their job'. Some went even further and stressed that because of the nature of the job, perhaps the military is not a place for intolerance of differences. One cadet fulminated:

I mean in terms of like how future problems that could come out of this and I think the biggest problem is going to be cohesion. People may not feel comfortable and you can't treat them [transgender people] any differently. In the long run they probably don't want to be treated differently; they probably want to be treated like a man or woman. And so don't treat them differently. Treat them exactly how you would anyone else and if you have any subordinates that don't like it or refuse to work with them then get out because the Army is shrinking and there's plenty of other people that would be willing to work with them and be able to accomplish a mission better.

The cadet goes on:

It makes me uncomfortable when people feel so strongly uncomfortable with people who are different than them. I do not feel like I need to hate gay people to be here [West Point]. I do not feel like gay people need to make me feel uncomfortable for me to be here. I do not feel like I have to be uncomfortable with Muslims to be here, but a lot of 
cadets are uncomfortable with Muslims and are uncomfortable with gay people and are uncomfortable with a lot of other things quite frankly. That is not necessarily a part of being a West Point cadet. I do not feel like that is part of the inherent value of being here. I feel like you can still have the Corps [of Cadets] and what it stands for and be an open minded and diverse organization. The Corps is a dynamic thing because as a leader you should be shifting with the world around you. Really. It is quite ridiculous that they did not let gay people in the Army in the first place. Why does it matter? Really, why does it matter?

A significant concern was that transgender cadets would feel stigmatized and potentially isolated. Below is one exchange between the moderator and two cadets after discussing a hypothetical; someone who has transitioned from male to female yet has an exceptionally high Army status marker, a Ranger Tab qualification decoration, signifying that they have completed a rigorous and coveted 61 day training school:

Moderator: What if she is now a woman and she is an absolute bad ass and oh, by the way, she has a Ranger Tab?

Cadet\#1: They are going to make jokes, most definitely.

Moderator: You still think they would make jokes? You think her transgender would trump a Ranger Tab?

Cadet \#2: I think people would look at her and look at her like she was born a male so it is not different. In my experience, people in the Army are very simple minded.

Last, virtually all the cadets and some of the officers expressed vehemently that any transsexuality (i.e., physiological changes) is a personal choice on the part of the individual. Further, and as an outcome, transitioning is an elective surgery and should absolutely not be covered or paid for by the military. A female cadet said ' 100 percent'. When asked more pointedly, 'So you think it's the wrong reason to join the Army to get medical care, medical benefits?' She then doubled down on her response. Another cadet stressed:

I would be against it [transsexual surgery in the military], this kind of elective, cosmetic surgery that requires kind of; it is the same as if you have got a condition that requires chronic medication because you are going through something that makes you incompatible [with military service]. I do not think the Army, the taxpayer, I do not think it is their job to accommodate that. I think that we have a responsibility to assess individuals who are stable and someone is no longer capable of military service, well, transition them with dignity as much as possible. But I do not think we have to, I do not think we have to help them change their identity. I think it is a disservice to taxpayers.

Yet, with some probes and collective discussion in the focus groups, cadets and military members challenged their logic and one another. One women responded after a discussion; 'I do not know, part of me wants to say yes because maybe that transitioning surgery would make an individual more effective'. Such nuanced responses emerged after some focus group discussion where other forms of elective surgery or procedures were evoked, such as vision alterations, breast reduction surgery, cosmetic forms of surgery, and even pregnancy, as 'choices' that are fully medically compensated for by the military.

\subsection{Interventions}

The last third of each focus group allowed respondents to put forth recommendations and solutions that they thought would assist in overcoming the major issues they had identified as being associated with transgender cadets and soldiers. The idea behind empowering the members of the focus group was to converge their level of knowledge about transgender matters with identifying, defining, and refining the major concerns. Anticipating the lifting of the ban on the military, the cadets 
and officers put forth a range of solutions that might be interpreted as fairly progressive for West Point and the military. They include logistical changes, encouraging people to overcome their biases, single physical training standards, gender-neutral bathrooms, education more than training, and compartmentalizing roles and leadership as professionals.

In terms of logistical changes, a most prominent recommendation centered on maintaining the current housing and roommate arrangements and creating more privacy. These included private rooms, if possible, but especially hygiene privacy, such as curtained showers and closed off stalls. Some suggested unisex living; most did not. A cadet said:

Well then it would be an easy call for me. I'd make the decision to have two separate barracks where if you identify as a male, then you'd be in one. If you identified as female, you'd be in one. It would just work like that.

Another said, 'I would never put a man and woman in the same barracks room'.

As many cadets also recommended a transparent approach to rooming, recommending an open policy of allowing people to choose their roommates. Cadets and soldiers would be encouraged to self-select someone with whom they would prefer to room.

Yet cadets also emphasized the need for fellow cadets, soldiers, and leaders to overcome their personal biases. One female cadet said; 'Get over your prejudices'. Another said, more pragmatically; 'It is a new, smaller Army, and there is no room for personal bias or intolerance against a protected group'. Finally, a most typical example was:

But at the same time, it presents bigger issues in the Tactical Officer [the legal representative of approximately 100 cadets] realm because if you, as you said, cater to a population, well what other populations do you now have to cater to? And you can continue to peel the layer of the onion back and how petty are roommate conflicts that we are now constantly shuffling a company because so and so just cannot get along for XY and $\mathrm{Z}$ reasons. So it speaks to a bigger issue of how far the tolerance level has to go before we just say no, you are rooming with so and so. Get over it. It is a semester. You can pick your roommate again next semester.

As noted, a major concern is physical training (PT) standards. Cadets stressed the most consternation, concern, and confusion about interventions for this issue. In terms of recommendations, many cadets argued to move to a single PT standard for both sexes. A minority recommended that performance of PT standards should be associated with one's original sex. A smaller minority attributed PT assignment to physical anatomy. One cadet asked; ' . . PT standards, right? So if you're halfway through your transition, what scale are you on? Female or male?' A male officer commented on the inequity of the PT standard. He said:

I think initially a lot of these separate PT standards were imposed or put in place by men. I know men that cannot perform very well on the male scale. I know women that can max it. It should not matter. So do away with stuff like that ... I know girls that could dust me in a PT test. Shoot. There is probably one in this room that could dust me at a PT test right now.

Gender-neutral or same-sex community rest rooms emerged as an intervention topic. The vast majority of cadets and faculty seem to favor moving toward some element of same-sex rest rooms, at least publically. One officer said 'Yes', to same-sex restrooms, pushing the envelope further; ' ... kind of like in the olden days when we had one giant slit trench. You're right next to your battle buddy. A little more privacy would be nice'. Another cadet said, 'I'd love to see it but first we should get some gender neutralness here. Like Ally McBeal bathrooms. I'm all for it' [36]. Finally, a cadet shared a comparative perspective legitimating gender-neutral/same-sex public restrooms: 
This past summer, I had the opportunity to visit a civilian college. I had never seen the third bathroom and the logo was, like they have the stick guy and the stick girl with the dress. The logo was half and half and it was just the first time I had ever; I mean, I had to take a picture of it.

Many cadets concurred that there must be more education and training about transgender issues in the military, both at West Point and in the larger U.S. Army. First, education as an intervention received the most positive comments. An officer said:

I think awareness and education is a large part of it. Thinking about other integration and inclusion challenges that have been faced in the recent past, whether it's gender inclusion, racial inclusion, sexual orientation inclusion. Generally, the path to finding a social common ground, an area where the majority of people in the group, the majority of people outside of whichever group we're talking about getting included, have reached a relatively comfortable place. In almost every case I can think of, the road to that begins with some sort of education/awareness. These people, just because they're different from you, it doesn't necessarily mean that they descended from space and are here to suck your brains out, that kind of thing.

A cadet stressed:

You really have to educate. You have to go through SHARP [Sexual Harassment/Assault Response and Prevention] training right, you have to go through different training, you have to go through transsexual training too, LBGT things, about how to work cohesively as a unit, so you are working together to fight the enemy. It is all about serving the country, it is not about individuals or individuality.

While education received overwhelming support, training, on the other hand, did not. Indeed, many recoiled at the thought of more mandatory training programs reinforcing recent research findings on the topic [37]. Below are typical responses to the need for training and education of cadets and soldiers. A junior level cadet confessed; 'Thank God there is no online gay/lesbian training where you've got to click through. I think that would not be good. Actually that is highly offensive'. Another pined:

It needs to be all of the above really. It is command climate. It is education. And it's training. In a balance. You can see just how the Army has dealt with that with something like SHARP or gays in the military. The first attempt to make it all about training usually ends up with some sort of cynical backfire.

Finally, some cadets stressed an experiential model. By simply being exposed to four years of college, having leaders lead on the issue, and being forced to interact with a host of others, would provide for a more inclusive work environment. Below is a notable response from a junior level cadet reflecting on the developmental process at West Point that represents the notion:

I would say it definitely progresses in a positive way because I think that, I mean, we constantly preach and harp on how a diverse team is the most effective team. I think all these opportunities, especially summer training, you really get to see that firsthand. So I think we kind of evolve and I know a lot of people are probably closed off. I mean I personally think I am open. But I went to Catholic School my whole life. So it is kind of, I will be honest, most people are pretty narrow minded there. They have a one track mind of how to do things. When you come here [West Point] and there are a million different religions, a million different kinds of people, it just forces you to deal with that and handle it. And I mean honestly, I have probably personally evolved. And I just think you really do see on your own how much of a difference it can make because you get people from 
all different walks of life. And so I think throwing us in the mix without really any choice forces you to evolve in a good way I think.

Last, in terms of interventions, we asked cadets and military members if they could lead and be led by transgender cadets and officers. Virtually all said yes in terms of leading. A typical response was; 'I could definitely lead. Somebody's gender does not really affect leading', and one cadet qualified her leadership ability by stating, 'Maybe I am just rah-rah West Point, but I feel like West Point should do it the best of anyone'. A plebe responded:

I think that I do not really know too much about leadership, but I think that if I had to lead today, I would want to get to know every single one of my soldiers personally. I would really try to get close with everyone, so I would try to get close with my transgender soldier and that would make me care for him or her. So yes I would advocate for them, especially if I developed that personal relationship. If they were being bullied or anything like that, that has no place in the Army.

We label the above views 'pragmatic professionalism'. In this sense, many can compartmentalize and subordinate their personal views, mores, and reservations for the greater mission as leaders. All confessed that they could curb their personal views, be a professional officer, and lead.

On the other hand, vertical cohesion down the chain of the command is fine, while up the chain of command is more problematic. Virtually all said they could lead; a few questioned subordinating to a transgender leader. A cadet said; 'If my leader doesn't know what he wants to be, why am I going to follow him or her in combat? That's what I would think to be honest. If you change your mind every day on what you want to be... ' Another cadet cautiously shared: 'Well, if they think something else should be going on, then they would be, I do not want to say making a habit out of it, but they would be bringing it up and making it an issue' [it referring to transgender status].

Related to the last quote, another minority of cadets felt comfortable leading, subordinating to, and serving as peers with transgender cadets and soldiers with a caveat; the transgender cadet or soldier should greatly subordinate their transgender identity. In other words, that they did not deploy their 'transgender' identity. Respondents agreed with the term 'flaunt' once the moderator used it, but the respondents did not say the term. When asked whether they could advocate on behalf of their super-ordinates and could serve under a transgender leader, their major criteria seemed associated with task ability, i.e., could they perform the duty? Of course, what we did not discuss was if they did fail at something, would it be attributed to their gender identity or just their ability? A male cadet said:

I feel like as long as they, I am going to look at their leadership ability and their actual qualities before and if they can do their job then, while I do not personally agree with that [trans], I am not going to deny them the opportunity to do their job or whatever. I am just personally, it might be a little hard for me to be, to not see it or overlook it, but I would not hold that against them necessarily when trying to work with them.

\section{Discussion and Conclusions}

Notably, the U.S. military projects, seeks, and demands a commonality of experience and a 'let's just get on with it ... ' orientation. Readers may be slightly startled as to how amenable cadets and officers here are to working with transgender service members, especially given findings showing that some of their civilian (and military) peers can be quite prejudiced $[25,26,30]$. Further, affinity groups have had a varied social history with integration [38], as have transgender people in other militaries [39]. We undertook an applied, qualitative study to explore the experiences, major concerns, and intervention that cadets and officers at West Point would have with anticipation of the integration of transgender cadets and service members. 
The disadvantages and subsequent limitations of the focus groups include limited generalizability, individual attributions in group settings, and a somewhat artificial context. The advantages of the focus group include the dynamic nature of the face-to-face interactions, depth of understanding, allowing participants to interact and giving them a voice, the moderators being organizational insiders, and the participants' ability to provide input into solutions to a real world policy change impacting the military. We feel that the advantages outweigh the disadvantages. However, the recommendations that follow should be considered within the context of the limitations of the study and of focus groups more generally [34].

Based on the above findings, we offer our recommendations tentatively as West Point, other American military academies, and the U.S. military have moved toward a more inclusive environment and integrate openly transgender service members into their ranks. First, education is needed for most cisgender service members. A number of features point to a need for education in the present study. Foremost, cadets and some officers seem to perceive transgender as a universal, binary, transsexual experience rather than an umbrella term for a host of gendered and sexual minorities. Given the level of 'uncomfortableness' reported among the cadets and their speculations about high school peers matriculating into the enlisted ranks of the Army, there lurks copious misinformation at best and elements of transphobia at the margins. Thus, sensible education and training would overcome misinformation and move toward healthy and effective cohesion. Research on mandatory diversity training in organizations, however, appears to have the opposite impact [37]. Cadets and officers report here that they abhor 'training' and perceive it as 'offensive'. Given the Army's propensity for efficiency on most matters, it is likely that training will be normative. We recommend some coupling of education with training based on the findings here.

By training, in this context, we mean an overemphasis on narrow, practical, short term, 'do's and don'ts' skilling for specific job performance, which lacks context. Training downplays the whole human and plays up specific human behaviors. By education, we mean a broader, theoretical, reasoned, and socio-historical contextual study of the issue. Education could include some practical considerations, but training tends to forgo education. Education humanizes transgender people more than training. For the military cadet, education occurs in the classroom with all the features of schooling, including a subject matter expert. Training more often occurs in the barracks, by peers, with little to no assessment. Cadet and officer preferences for learning about transgender people should include many features of education. That education might begin with the many reasons women dressed as men to go into combat during earlier wars [40] and the fact that a former U.S. soldier and native New Yorker named George Jorgensen (later Christine Jorgensen) became the first 'out' American person, having undergone sexual reassignment surgery in 1952 [41].

Second, we adopt two labels from the business literature to categorize familiarity and engagement with transgender people; tourists versus cosmopolitans. For many cadets and officers with no direct familiarity or experience with the transgender community, we label them 'tourists'. Tourists in this context are spectators in alien communities and cultures. Transgender tourists are those that might be aware of Caitlyn Jenner, Laverne Cox, or Chaz Bono via the mass media but are unfamiliar with and lack access to the everyday transgender community. They lack the cross-group competence and the cultural capital to connect with transgender cadets. At the other end of spectrum are 'cosmopolitans', people with a willingness to enter, participate, engage, and even feel at home in alien cultures and communities [42]. Transgender cosmopolitans are cadets and officers that have experience and knowledge about the transgender community, are curious about it, and are comfortable with entering and engaging members of the community. They seem to be sub-culturally competent and possess cultural capital to bond with transgender comrades-in-arms and civilians. Further, cosmopolitans are empathetic about transgender people being tokens in the military community. 
Third, being a tourist and cosmopolitan is learned behavior and is dynamic. Cosmopolitans can help in the education and training of tourists and help with unit cohesion. This can be done through some small group learning opportunities similar to the officer that got over his 'uncomfortableness' at dinner with a newly rediscovered, old, transgender friend.

Fourth, millennials as a generation have a desire for intimate privacy but less so for digital privacy [43]. Given the generation and our findings, West Point and the Army should consider the impact of privatizing living quarters (at least in garrison), especially sleeping and hygiene, while concomitantly preparing and training service members to live sparingly, openly, and gender-neutrally in real-world military environments.

Fifth, narrow the civilian-military propinquity gap. West Point and Army posts in particular are located in mostly rural areas, and military members have their tourism reinforced in these rural areas. To narrow the civilian-military gap, increase opportunities for engaging urban areas and the range of communities that exist there. For example, all of the officers in our focus groups had advanced civilian schooling beyond an undergraduate degree. They are more gender cosmopolitan than their peers through not only their leadership acumen and education but also through experiences with peers in graduate schools in such places as Columbia University in New York City and the University of Maryland near Washington D.C.

Last, we recommend that West Point and the Army continue to move toward recognizing that transgender people and their collectively unique issues are not socially isolated but are rather connected to a broader set of issues associated with diversity and inclusion, physical fitness, professionalism, first-class citizenship, vertical and horizontal cohesion, and leadership. The sponsoring of the present study is one such example. More broadly, the Implementation Handbook has a bottom line point that people should ' ... treat others with the dignity, respect, and consideration you would like to be treated with by others' [6].

Looking ahead, given some of the lack of information and misinformation about transgender issues discovered here, experiences with integrating groups historically, and the fact that West Point and the Army have become increasingly inclusive organizations, there must be ongoing support, encouragement, and undertaking of research on diversity topics. The focus on especially nuanced topics associated with invisible sexual and gendered minorities including queer, undecided, intersexed, lesbian, transgender, bisexual, asexual, and gay (QUILTBAG) is warranted, given the proclivity for groups to be silenced in organizations [44].

Finally, there is a long tradition of studying the intersections of different groups, military service, citizenship, cohesion, and diversity in military organizations [45]. Future research should look to replicate the findings reported here with service members at multiple levels of the organization. Further, some research suggests, for example, a faulty urban versus rural binary narrative regarding attitudes toward LGB people [46]. How do the findings here regarding transgender people contribute to this literature and our understanding of transgender experiences? Research is slightly inconclusive regarding the intersection of unit cohesion and sexual/gender non-conformity [19,47]. Studies should monitor both LGBT and non-LGBT people and their units over time. Finally, more broadly, what are the long term implications? Millennials such as the ones participating in the focus groups undertaken in this study should be followed into the military to assess if their tolerance remains, expands, or subsides as the micro and macro cultures between and within the various services shape their perspective. Clearly, West Point and the U.S. Army cannot afford to be a diversity champion on one front only to lose on the inclusion front.

Acknowledgments: The authors wish to thank Larry Wark, Mary Krueger, Kelly Ervin, Bernie Banks, our cadet and active duty service member participants, and two anonymous reviewers for their inspiration and assistance on making this article possible. Partial funding for this project is supported by the Faculty Development Research Fund, Office of the Dean at the United States Military Academy at West Point and the Assistant Secretary of the Army, Manpower \& Reserve Affairs, Office of Military Personnel \& Quality of Life. The views expressed in this article are those of the authors and do not reflect the official policy or position of the United States Military Academy, the Department of the Army, the Department of Defense, or the United States Government. 
Author Contributions: Morten G. Ender conceived, designed, and participated in each phase of the study including the overall writing of the paper. Diane M. Ryan, Danielle A. Nuszkowski, Emma Sarah Spell and Charles B. Atkins participated in reviewing the literature, data collection, data analysis, and contributing to sections and drafts of the paper. The division of labor of the authors is represented by their subsequent author order.

Conflicts of Interest: The authors declare no conflict of interest.

\section{References}

1. Buzz Bissinger. “Caitlyn Jenner: The Full Story." Vanity Fair,. July 2015. Available online: http:/ /www.vanityfair. com/hollywood/2015/06/caitlyn-jenner-bruce-cover-annie-leibovitz (accessed on 23 November 2016).

2. Andrea M. Hackl, Amy B. Becker, and Maureen E. Todd. "“I Am Chelsea Manning”: Comparison of Gendered Representation of Private Manning in U.S. and International News Media." Journal of Homosexuality 63 (2016): 467-86. [CrossRef] [PubMed]

3. Matthew F. Kerrigan. “Transgender Discrimination in the Military, The New Don't Ask, Don't Tell." Psychology, Public Policy, and Law 18 (2013): 500-18. [CrossRef]

4. Adam F. Yerke, and Valory Mitchell. “Transgender People in the Military: Don't Ask? Don't Tell? Don't Enlist! " In Evolution of Government Policy towards Homosexuality in the US Military: Rise and Fall of DADT. Edited by James E. Parco and David A. Levy. London and New York: Routledge, 2014, pp. 307-28.

5. Jean R. Freedman. "Albert Cashier's Secret." New York Times, 28 January 2014. Available online: http:/ /opinionator.blogs.nytimes.com/2014/01/28/albert-cashiers-secret/?_php=true\&_type=blogs\&_r=0 (accessed on 30 August 2016).

6. Department of Defense. Transgender Service in the U.S. Military: An Implementation Handbook. Washington: Department of Defense, 2016.

7. Judith E. Rosenstein. "The Integration of Trans People in the Military and Military Family." In A Force for Diversity: The Past, Present, and Future of Inclusion in the U.S. Armed Forces. Edited by David E. Rohall, Morten G. Ender and Michael D. Matthews. Lanham: Lexington Books, 2017, forthcoming.

8. M. Joycelyn Elders, George R. Brown, Eli Coleman, Thomas A. Kolditz, and Alan M. Steinman. "Medical Aspects of Transgender Military Service." Armed Forces E Society 41 (2014): 199-220. [CrossRef]

9. Karl Bryant, and Kristen Schilt. Transgender People in the US Military: Summary and Analysis of the 2008 Transgender American Veterans Association Survey. Santa Barbara: Palm Center, 2008.

10. George R. Brown. "Transsexuals in the Military: Flight into Hypermasculinity." Archives of Sexual Behavior 17 (1988): 527-37. [CrossRef] [PubMed]

11. George R. Brown, and Kenneth T. Jones. "Mental Health and Medical Health Disparities in 5135 Transgender Veterans Receiving Healthcare in the Veterans Health Administration: A Case-Control Study." LGBT Health 3 (2016): 122-31. [CrossRef] [PubMed]

12. Jillian C. Shipherd, Lauren Mizock, Shira Maguen, and Kelly E. Green. "Male-to-Female Transgender Veterans and VA Health Care Utilization." International Journal of Sexual Health 24 (2012): 78-87. [CrossRef]

13. Sandy E. James, Jody L. Herman, Susan Rankin, Mara Keisling, Lisa Mottet, and Ma'ayan Anafi. The Report of the 2015 U.S. Transgender Survey. Washington: National Center for Transgender Equality, 2016.

14. John R. Blosnich, George R. Brown, Jillian C. Shipherd, Michael Kauth, Rebecca I. Piegari, and Robert M. Bossarte. "Prevalence of Gender Identity Disorder and Suicide Risk among Transgender Veterans Utilizing Veterans Health Administration Care." American Journal of Public Health 103 (2013): e27-e32. [CrossRef] [PubMed]

15. James E. Parco, David A. Levy, and Sarah R. Spears. "Transgender Military Personnel in the Post-DADT Repeal Era: A Phenomenological Study." Armed Forces \& Society 41 (2015): 221-42. [CrossRef]

16. Joshua Polchar, Tim Sweijs, Philipp Marten, and Jan Hendrik Galdiga. "LGBT Military Index." Available online: http:/ / projects.hcss.nl/monitor/88/ (accessed on 9 October 2016).

17. Thomas Crosbie, and Marek N. Posard. "Barriers to Serve: Social Policy and the Transgendered Military." Journal of Sociology 52 (2016): 569-85. [CrossRef]

18. Alan Okros, and Denise Scott. "Gender Identity in the Canadian Forces: A Review of Possible Impacts on Operational Effectiveness." Armed Forces \& Society 41 (2015): 243-56. [CrossRef]

19. Agnes Gereben Schaefer, Radha Iyengar, Srikanth Kaiyala, Jennifer Kavanagh, Charles C. Engel, Kayla M. Williams, and Amii Kress. Assessing the Implications of Allowing Transgender Personnel to Serve Openly. Santa Monica: RAND Corp, 2016. 
20. Gregory M. Herek, and Aaron Belkin. "Sexual Orientation and Military Service: Prospects for Organizational and Individual Change in the United States." In Military Life: The Psychology of Serving in Peace and Combat, Military Culture. Edited by Thomas W. Britt, Amy B. Adler and Carl Andrew Castro. Westport and London: Praeger Security International, 2006, vol. 4, pp. 119-42.

21. Gregory M. Herek. "Legal Recognition of Same-Sex Relationship in the United States: A Social Science Perspective." American Psychologist 61 (2006): 607-21. [CrossRef] [PubMed]

22. James E. Parco, and David A. Levy, eds. Evolution of Government Policy towards Homosexuality in the US Military: Rise and Fall of DADT. London and New York: Routledge, 2014.

23. Aaron T. Norton, and Gregory M. Herek. “Heterosexuals' Attitudes toward Transgender People: Findings from a National Probability Sample of US Adults." Sex Roles 68 (2013): 738-53. [CrossRef]

24. Michael Woodford, Michael R. Brittanie Atteberry, Matthew Derr, and Michael Howell. "Endorsement for Civil Rights for Lesbian, Gay, Bisexual, and Transgender People among Heterosexual College Students: Informing Socially Just Policy Advocacy." Journal of Community Practice 21 (2013): 203-27. [CrossRef]

25. María Carrera-Fernández, María Lameiras-Fernández, Yolanda Rodrígues-Castro, and Pablo Vallejo-Medina. "Spanish Adolescents' Attitudes toward Transpeople: Proposal and Validation of a Short Form of the Genderism and Transphobia Scale." The Journal of Sex Research 51 (2013): 654-66. [CrossRef] [PubMed]

26. Laural Holland, Todd L. Matthews, and Melinda R. Schott. “'That's So Gay!' Exploring College Students' Attitudes toward the LGBT Population." Journal of Homosexuality 60 (2013): 575-95. [CrossRef] [PubMed]

27. Pam Nicol, Rose Chapman, Rochelle Watkins, Jeanine Young, and Linda Shields. “Tertiary Paediatric Hospital Health Professionals' Attitudes to Lesbian, Gay, Bisexual and Transgender Parents Seeking Health Care for Their Children." Journal of Clinical Nursing 22 (2013): 3396-405. [CrossRef] [PubMed]

28. Michael R. Woodford, David J. Brennan, Lorraine Gutiérrez, and Katherine P. Luke. "US Graduate Social Work Faculty's Attitudes toward Lesbian, Gay, Bisexual, and Transgender People." Journal of Social Service Research 39 (2013): 50-62. [CrossRef]

29. Michael D. Matthews, Morten G. Ender, Janice Laurence, and David E. Rohall. "Role of Group Affiliation and Gender Attitudes toward Women in the Military." Military Psychology 21 (2009): 241-51. [CrossRef]

30. Morten G. Ender, David E. Rohall, Andrew J. Brennan, Michael D. Matthews, and Irving Smith. "Civilian, ROTC, and Military Academy Undergraduate Attitudes toward Homosexuals in the US Military." Armed Forces \& Society 38 (2012): 164-72. [CrossRef]

31. Morten G. Ender, David E. Rohall, and Michael D. Matthews. "Cadet and Civilian Undergraduate Attitudes toward Transgender People: A Research Note." Armed Forces \& Society 42 (2016): 427-35. [CrossRef]

32. Cynthia A. Watson. Military Education: A Reference Handbook. Westport: Praeger, 2007.

33. George B. Forsythe, and Bruce Keith. “The Evolving USMA Academic Curriculum, 1952-2002." In West Point: Two Centuries and Beyond. Edited by Lance Betros. Abiline: McWhiney Foundation Press, 2004, pp. 370-89.

34. Brenda L. Moore. "In-Depth Interviewing." In Routledge Handbook of Research Methods in Military Studies. Edited by Joseph Soeters, Patricia M. Shields and Sebastiaan Rietjens. Oxon and New York: Routledge, 2014, pp. 116-28.

35. Verta Taylor, and Leila J. Rupp. "Chicks with Dicks, Men in Dresses: What It Means to Be a Drag Queen." Journal of Homosexuality 46 (2004): 113-33. [CrossRef] [PubMed]

36. Youtube.com. "Ally McBeal and the Unisex Bathroom." Available online: https://www.youtube.com/ watch?v=AYUavFaQwEw (accessed on 1 October 2016).

37. Frank Dobbin, and Alexandra Kalev. "Why Diversity Programs Fail." Harvard Business Review, July-August 2016. Available online: https://hbr.org/2016/07/why-diversity-programs-fail (accessed on 23 November 2016).

38. David E. Rohall, Morten G. Ender, and Michael D. Matthews, eds. A Force for Diversity: The Past, Present, and Future of Inclusion in the U.S. Armed Forces. Lanham: Lexington Books, 2017, forthcoming.

39. Noah Riseman. "Transgender Policy in the Australian Defence Force: Medicalization and its Discontents." International Journal of Transgenderism 17 (2016): 141-54. [CrossRef]

40. Julie Wheelwright. Amazons and Military Maids: Women Who Dressed as Men in the Pursuit of Life, Liberty and Happiness. London: Pandora Press, 1989.

41. Joanne Meyerowitz. How Sex Changed: A History of Transsexuality in the United States. Cambridge: Harvard University Press, 2002.

42. Mark Cleveland, and Michael Laroche. "Acculturation to the Global Consumer Culture: Scale Development and Research Paradigm." Journal of Business Research 60 (2006): 249-59. [CrossRef] 
43. Neil Howe, and William Strauss. Millennials Rising: The Next Great Generation. New York: Vintage, 2000.

44. Vincenza Priola, Diego Lasio, Silvia De Simone, and Francesco Serri. "The Sound of Silence: Lesbian, Gay, Bisexual and Transgender Discrimination in 'Inclusive Organizations'." British Journal of Management 25 (2014): 488-502. [CrossRef]

45. David R. Segal, Mady Wechsler Segal, and Brian J. Reed. "Diversity and Citizenship in Modern Military Organization." Turkish Journal of Sociology 35 (2015): 43-61. [CrossRef]

46. Catherine Connell. "Different than an Infantry Unit down in Georgia: Narratives of Queer Liberation in the Post-DADT Military." Sexualities, 2017, in press.

47. Aaron Belkin, Morten G. Ender, Nathaniel Frank, Stacie Furia, George R. Lucas, Gary A. Packard, Steven M. Samuels, Tammy S. Schultz, and David R. Segal. One Year Out: An Assessment of DADT Repeal's Impact on Military Readiness. Edited by James E. Parco and David A. Levy. London and New York: Routledge, 2014, pp. 329-73.

(C) 2017 by the authors. Licensee MDPI, Basel, Switzerland. This article is an open access article distributed under the terms and conditions of the Creative Commons Attribution (CC BY) license (http:/ / creativecommons.org/licenses/by/4.0/). 